\title{
Technical Difficulty in the NICU
}

Kelly Welton, BA, RRT-NPS

\section{"As an educator, it's one thing to get staff to study and read about how the equipment works. And another thing to show people how things work, and then require a return demonstration. Requiring them to utilize their critical thinking skills on the spot is another story."}

Ouch. I just smacked my head again. This is the third call in as many days from the NICU medical director. The transport ventilator is broken. Again. The baby just got out of surgery, is in the transport isolette, and the ventilator won't run. "Whose job is it to ensure the ventilator works?!? Didn't BioMed fix this yesterday?! Aren't your RT's supposed to check this thing every morning??!" Ours, yes, and yes, I tell her. But the ventilator is not the problem.

As an educator, it's one thing to get staff to study and read about how the equipment works. And another thing to show people how things work, and then require a return demonstration. Requiring them to utilize their critical thinking skills on the spot is another story.

What exactly are "critical thinking skills," and how can one assess if another person has these mysterious powers?

I set out to answer this question a few years back in a survey sent to RT managers across the US.

\section{Definition of Critical Thinking}

Critical Thinking skills are a desirable trait in health care professionals. However, there is much debate about how critical thinking skills are acquired and how they can be measured.

The results from the RT Manager survey revealed several definitions:

- "The ability to assess a situation, to see the whole picture"

- $\quad$ "The ability to analyze multiple sensory inputs and identify options for appropriate responses"

- $\quad$ "The ability to think through and then anticipate where they are going."

- $\quad$ "The ability to analyze a situation and select a course of action"

- $\quad$ "Seeing and processing what you see and know."

The community, criticalthinking.org states: "Critical thinking is self-di- rected, self-disciplined, self-monitored, and self-corrective thinking."

Most hospitals put their staff through an annual competency review. Someone has to check off each therapist on equipment and procedures used by their department. Many new and seasoned RT's can pass an equipment competency, such as setting up and managing a certain type of ventilator, or a procedure competency, resulting in an ABG with a critical value. In an ideal situation, nothing would go wrong. No exhalation valve leaks, no patient desaturating in the middle of a procedure would occur. Annual competencies may or may not include 'what - if' scenarios to allow RT's to show that they can think on their feet, so to speak.

Competence, in the RT setting, refers to an individual's ability to perform a task. A competent person may also be able to troubleshoot basic problems. Competency assessments, therefore, can vary from hospital to hospital. For example, an RT that passes annual competency on a NICU ventilator at a Level I NICU facility may have a very different actual skill level than an RT who passes an annual competency on the same ventilator at a Level III NICU.

"Competence, in the RT setting, refers to an individual's ability to perform a task. A competent person may also be able to troubleshoot basic problems. Competency assessments, therefore, can vary from hospital to hospital."

One very significant point is that health care workers acquire competence over time. (1) However, even the most proficient expert at something - calibrating an ABG analyzer, for example - does not mean they possess critical thinking skills to handle the unexpected. They may have memorized each step, anticipating only a green light to complete the next task.

\section{Examples of Critical Thinking}

MR SOPA in NRP

If the RT finds they have difficulty ventilating via bag-valve-mask when resuscitating a baby, they are taught the "MR SOPA" acronym. Mask, Reposition head, Suction mouth and then the nose, Open mouth, adjust Pressure, Airway. While these are the correct steps, an experienced RT would go through these steps without thinking. A newer, occasional NICU/newborn RT will practice those steps and the mnemonic until the steps become automatic.

\section{Classifying Critical Thinking}

Some thought leaders think of critical thinking as an 'If $\rightarrow$ Then'

NEONATOLOGY TODAY is interested in publishing manuscripts from Neonatologists, Fellows, NNPs and those involved in caring for neonates on case studies, research results, hospital news, meeting announcements, and other pertinent topics.

Please submit your manuscript to: LomaLindaPublishingCompany@gmail.com 
process as if all possibilities for the next steps have been neatly laid out in a decision tree.

Others consider it simply "anticipating next steps." The majority of respondents classified critical thinking as both.

These ideas can apply to equipment, patients, or situations:

- If the ventilator is not pressurizing, there must be a leak or disconnect

- If the patient's chest is not rising on inspiration, the set PIP may be too low.

- If the patient is connected to the ventilator, but the sat's are $77 \%$, I need to bag.

\section{Are Critical Thinking Skills Teachable?}

If acquiring critical thinking skills requires experience, it would be nearly impossible to teach critical thinking in the classroom. But what about in the clinical setting? By the time the student has learned to do $A$, then $B$, then step $C$, and then performs these steps at the bedside, does that allow the student to think critically?

Often, RT and Nursing schools are burdened with attaining a certain pass rate, so instructors and students are most interested in 'the right answer' rather than next steps or outlier possibilities.

\section{But back to the transporter dilemma.....}

Baby in surgery 2 hours = tanks emptied

The Crossvent2i ventilator, like many others, is a pneumaticallypowered infant transport ventilator. There is a set flow to achieve pressure during a set I-time. There is also a 'logic gas' flow, which powers the ventilator. If flow-triggering is chosen, that also requires an additional amount of flow through the ventilator.

But this was not a math or calculation problem.

No matter how many times the staff were told to turn off the TANKS and not just the ventilator after a transport, that small fact was repeatedly forgotten. And now, for about the tenth time, we have a post-op intubated baby in the transporter and no way to ventilate. This tenth iteration of the same incident prompted the national survey.

The Root cause analysis was complete: No equipment malfunctions, just user error.

In the interest of safety, self-inflating bags were added to the transporter.

Although many would consider this a "Plan B" solution, Plan A (acquisition of Critical Thinking skills) still takes time, repetition, and experience.

\section{"Although many would consider this a "Plan B" solution, Plan A (acquisition of Critical Thinking skills) still takes time, repetition, and experience."}

\section{References:}

1. Benner, P. (1984). From novice to expert: Excellence and power in clinical nursing practice. Menlo Park: Addison-Wesley, pp. 13-34.

Disclosures: The author is President of the Academy of Neonatal Care, A Delaware 501 C (3) not for profit corporation.

NT
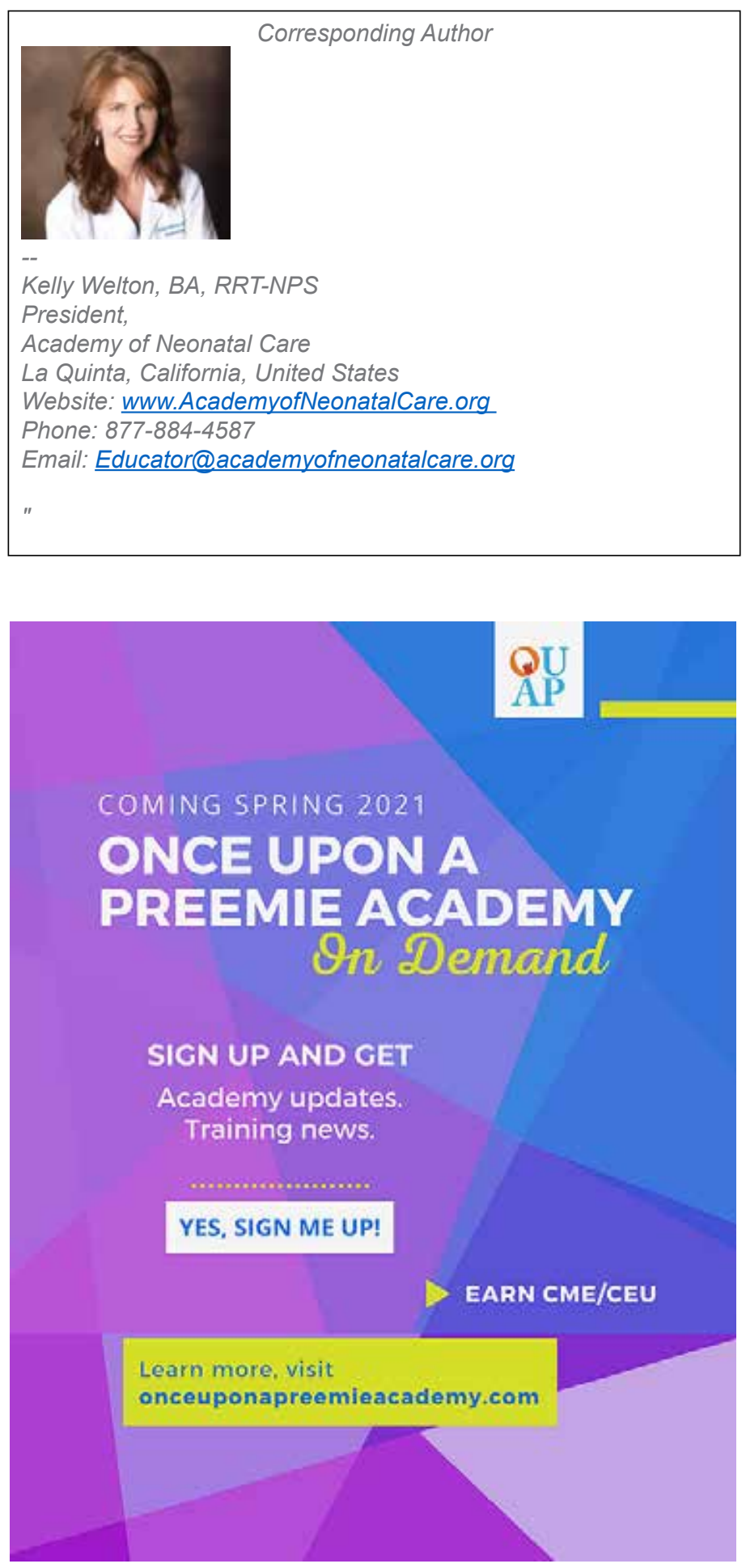

Readers can also follow NEONATOLOGY

via our Twitter Feed

@NEOTO 